\title{
Persistent Lymphopenia After Diagnosis of COVID- 19 Predicts Acute Respiratory Distress Syndrome: A Retrospective Cohort Study
}

\section{Zhiye Zou}

Shenzhen Second People's Hospital https://orcid.org/0000-0002-4100-568X

\section{Rong-ling Chen}

Longgang Central Hospital of Shenzhen

\section{Bao-jun Yu}

bao'an people's hospital of shenzhen

\section{Di Ren}

Shenzhen Second People's Hospital

\section{Yong-wen Feng}

Shenzhen Second People's Hospital

\section{Ming Wu ( $\nabla$ boshiyy@126.com )}

Department of Critical Care Medicine and Infection Prevention and Control, The Second People's Hospital of Shenzhen, 3002 Sungang West Road, Futian District, Shenzhen 518035, People's Republic of China https://orcid.org/0000-0002-0800-5506

\section{Research}

Keywords: Lymphopenia, acute respiratory distress syndrome, Coronavirus disease-2019

Posted Date: September 2nd, 2020

DOI: https://doi.org/10.21203/rs.3.rs-66910/v1

License: (a) (1) This work is licensed under a Creative Commons Attribution 4.0 International License. Read Full License

Version of Record: A version of this preprint was published at European Journal of Inflammation on January 1 st, 2021 . See the published version at https://doi.org/10.1177/20587392211036825. 


\section{Abstract}

BACKGROUND: Acute respiratory distress syndrome (ARDS) is a main characterized by severe Coronavirus disease-2019(COVID-19). Lymphopenia is a marker of immunosuppression following infection. This study was designed to establish whether persistent lymphopenia on the seventh day following the diagnosis of COVID-19 predicts ARDS.

METHODS: A retrospective cohort study of 125 patients with COVID-19 admitted to governmentdesignated treatment center between January 14, 2020, and March 20, 2020. All complete blood cell counts during the day 0th, 3rd, and 7th following the diagnosis of COVID-19 were recorded. Patients were grouped based on the depression of the lymphocyte cell count, their return, or their failure to normal. The primary outcome was ARDS, and Secondary outcomes included the development of vital organ dysfunction and hospital lengths of stay.

RESULTS: $17.6 \%(22 / 125)$ patients developed ARDS. The lymphocyte counts with ARDS and non-ARDS were $0.94 \times 10^{9} / \mathrm{L}, 1.20 \times 10^{9} / \mathrm{L}$ at admission, respectively $(P=0.02)$. At $3 \mathrm{rd}$ and 7 th day, the median of lymphocyte count in ARDS was significantly lower compared with that of non-ARDS, Multivariable logistic regression adjusting for potentially confounding factors (including age, comorbidities, APACH II score) showed persistent lymphopenia within 7th day was found to be independently associated with ARDS (OR, 3.94 [95\% Cl, 1.26-12.33, $\mathrm{P}=0.018)$; Further, patients with persistent lymphopenia had longer hospital lengths of stay $(p<0.001)$.

CONCLUSION: The results showed persistent lymphopenia on the seventh day following the confirmed COVID-19 predicts ARDS『and it may be a target for immunostimulation for COVID-19 associated ARDS.

\section{Introduction}

Coronavirus disease-2019(COVID-19) is a systemic infectious disease mainly caused by severe acute respiratory syndrome coronavirus 2(SARS-CoV-2), which enters host cells through angiotensin-converting enzyme 2 (ACE2) mediated SARS-CoV-2, leading to host severe inflammatory response(1). Immune and inflammation are critically involved in the process of SARS-CoV-2 infection. In many cases, dysregulated host response results in prolonged periods of immunosuppression with sepsis $(2,3)$. Previous reports the mortality was $62 \%$ among critically ill patients with COVID-19 and $81 \%$ among those requiring mechanical ventilation in Wuhan(4). COVID-19 induced dysregulation of innate and adaptive immunity prevents pathogen clearance and predispose to secondary infections, as evidenced by autopsy studies that had demonstrated ongoing foci of infections and functional defects in immune effector cells in patients who have died of COVID-19(5). The influence of COVID-19 on the human body is like a combination of severe acute respiratory syndrome (SARS) and Acquired Immune Deficiency Syndrome (AIDS). It damages both the lungs and immune systems. This immune dysfunction is a primary cause of late mortality in sepsis $(6,7)$. 
Clinical studies have demonstrated that prolonged lymphopenia is a candidate marker of persistent immunosuppression in patients with sepsis(8). Wu et al. (9) also reported that lymphocyte counts at admission were associated with the development of ARDS (HR0.37, P<.001), as they did not dynamically observe the relationship between lymphocyte counts and ARDS, and the relationship between them is not fully elucidated. Absolute lymphocyte counts are easily measured during routine care. Therefore, we aimed to identify the pattern of lymphocyte response to COVID-19 and determine whether persistent lymphopenia over the first seven days after admission to the hospital was associated with the development of ARDS. We hypothesized that developing lymphopenia shortly after the COVID-19, followed by rapid recovery to normal within the first seven days is typical. Suppose a deviation from this pattern would be associated with ARDS, which develop secondary vital organ dysfunction. Consequently, immune stimulation therapy strategies would be applied before rapid recovery to normal as early as possible.

\section{Materials And Methods}

\section{Study Design, setting and Participants}

This retrospective cohort study was designed by the investigators and reported its results in accordance with the STROBE(Strengthening the Reporting of Observational Studies in Epidemiology) guidelines and performed at the Third People's Hospital of Shenzhen between January 14, 2020, and March 10, 2020. The data cutoff for the study was March 25, 2020. The Human Research Protection Office approved data collection and analysis at our institution with a waiver of informed consent. Data were obtained from 149 patients with COVID-19 hospitalized at the Department of Critical Care Medicine and Infection Third Ward during the study dates. A confirmed case of COVID-19 was defined as a positive result on real-time reverse-transcriptase-polymerase-chain-reaction (RT-PCR) assay of pharyngeal swab specimens by Shenzhen center for disease prevention and control (CDC). The discharges criterion was negative two times 24-hour interval result on RT-PCR assay of pharyngeal swab specimens by Shenzhen CDC. The study analyzed de-identified data from the hospital's healthcare informatics group, which was supervised by the Shenzhen Municipal Health Commission. The Second People's Hospital approved the study protocol of Shenzhen \& First Affiliated Hospital of Shenzhen University (institutional review board number 202003009004).

Exclusion criteria included without lymphocyte count for three consecutive days on day 0 , day 3 , day 7 , and without lymphocyte count for two consecutive days on day 3 , day 7 .

\section{Data Collection and definitions}

Patient identification-a confirmed case of COVID-19 was defined as a positive result on real-time reversetranscriptase-polymerase-chain-reaction (RT-PCR) assay of pharyngeal swab specimens by Shenzhen center for disease prevention and control (CDC) during the study period. The discharges criterion was negative two times 24-hour interval result on RT-PCR assay of pharyngeal swab specimens by Shenzhen CDC. 
Leukocyte counts-The data for blood tests that were collected from the labs that were drawn as a standard of care. Every Complete Blood Cell count (CBC) (including the white blood cell count (WBC), neutrophil count, lymphocyte count, and monocyte count) that was obtained for day0, day3, day7, day 14 from admission on these patients was extracted from the medical record. If multiple leukocyte counts were collected within any 24-h period, the nadir value was documented for that period.

Definitions-Lymphopenia was defined as an absolute lymphocyte count less than $1.0 \times 10^{9} / \mathrm{L}$, which is lower than the limit of normal $\left(1.1 \times 10^{9} / \mathrm{L}\right)$ at our institution. The absolute lymphocyte count was segregated into three groups. One consisted of patients who did not develop lymphopenia within the first seven days after admission. Another consisted of patients who developed lymphopenia, which never returned to normal within the first seven days after admission. The other is to develop a decreased lymphocyte count which returns to normal within the first 7 days after admission. Persistent lymphopenia was defined as whose lymphocyte count did not return to normal within the first seven days after admission. Shock and acute respiratory distress syndrome (ARDS) were defined in accordance with the WHO interim guidance(10). Vital organ injury-Acute kidney injury was defined based on Kidney Disease: Improving Global Outcomes Clinical Practice Guidelines (KDIGO)(11). Acute cardiac dysfunction was defined as the clinical syndrome characterized by typical symptoms that may be accompanied by signs or elevated biomarkers of myocardial injury. Acute hepatic injury was defined as a state in which the patient's blood laboratory results met at least one of three criteria: total serum bilirubin (TBil) of 3.0 $\mathrm{mg} / \mathrm{dL}$ or greater; aspartate aminotransferase (AST) of $41 \mathrm{IU} / \mathrm{L}$ or higher; alanine aminotransferase (ALT) of $41 \mathrm{IU} / \mathrm{L}$ or higher; The patients who met none of these criteria were classified as the "normal liver function" group(12).

Baseline characteristics-Detailed chart review was then performed to exclude patients based on inclusion and exclusion criteria and to collect demographic and outcome data. For every patient, all routinely collected vital signs and symptoms, and laboratory values were extracted from the electronic health records. Data included, but were not limited to, demographic data (e.g., age, gender, body mass index [BMI]), biochemical parameters (e.g., blood cell count, liver function, kidney function, coagulation function, blood gas analysis), mechanic ventilation and comorbidities including hypertension, diabetes, cerebrovascular disease, chronic obstructive pulmonary disease (COPD), and malignancy for the severity of illness. We calculated the Acute Physiology and Chronic Health Evaluation (APACHE) II score within the first 24 hours of hospitalization. The study analyzed de-identified data from the hospital's healthcare informatics group, which was supervised by the Shenzhen Municipal Health Commission.

\section{Main Measures and outcomes}

The primary outcome was ARDS, and the Secondary outcomes included the development of vital organ dysfunction and hospital lengths of stay.

\section{Statistical Analysis}


The categorical data were summarized as numbers and percentages, and inter-group comparisons were performed using $\chi 2$ tests or Fisher's exact test. Continuous variables were expressed as the arithmetic mean and standard deviation (SD) or as the median and interquartile range, depending on whether or not they showed a Gaussian distribution. Continuous data with Gaussian distribution were compared with the Student's t-test or one-way ANOVA and those with a non-gaussian distribution, with the Wilcoxon ranksum test. To compare the white blood cell, lymphocytes, neutrophils and monocyte count between ARDS and non-ARDS groups over time and to correlate for within-subject correlation, a linear mixed-effect model was used with an autoregressive covariance structure. To determine the independent effect of persistent lymphopenia on ARDS after accounting for significant confounders, multivariable logistic regression with a forced entry method was used with crude model and fully adjusted model: OR (odds ratioهand $95 \%$ confidence interval levels $(95 \% \mathrm{Cl})$. The predictive ability of lymphocyte count on day0, day3, and day7 were assessed using the AU-ROC curve method. Youden's index determined the optimal cutoff value. Statistical analysis was performed using the statistical package SAS 9.4 (Windows, SAS Institute, Cary, North Carolina) and the R software (version 3.6.2). P values (two-tailed) below 0.05 were considered statistically significant.

\section{Results}

\section{Demographics and baseline characteristics associated COVID-19}

The detailed demographic and clinical profile data of all patients with COVID-19 on baseline were summarized in Table 1. By February 11, 2020, clinical data were collected in 149 patients in the Department of Critical Care Medicine and Infection Third Ward with laboratory-confirmed COVID-19. A total of 125 patients were included in the study (Fig. 1). Twenty-two patients (17.6\%) had been confirmed ARDS. Table 1 reports the baseline characteristics of the entire patient cohort. ARDS patients were older and had lower with Hubei exposure, more proportion of admission to ICU(63.6\% vs. 23.3\%), higher inflammatory biomarker and Organ function parameters (PCT, CRP, IL-6, Neutrophils, NLR, PLR, ALT, AST, D-Dimer, FIB, APACHE II score) and but lower in Lymphocyte, albumin, $\mathrm{PO}_{2} / \mathrm{FiO}_{2}$, Cholinesterase without more comorbidities.

\section{Characteristics and outcomes of patients stratified lymphocyte count within the first seven days}

The included patients were divided into three groups: no lymphopenia(n=79), persistent lymphopenia( $n=35)$, and lymphocyte counts returned to normal $(n=11)$ within the first seven days after admission. 28\% (35/125) had been diagnosed with persistent lymphopenia. The baseline characteristics of the three groups were shown in Table 2. Patients with persistent lymphopenia were older and had a higher incidence of comorbidities (hypertension), lower Hubei exposure, more invasive and noninvasive ventilation, and had a higher APACHE II score. Persistent lymphopenia patients had a higher incidence of AKI, shock, ARDS, admission to ICU, and longer length of stay. Fig 2 showed the box plots of leukocyte counts in ARDS and non-ARDS on day0, day3, day7, day14after admission. There was a significant difference in the WBC, absolute lymphocyte count, and absolute neutrophil count in ARDS and non-ARDS, 
but no difference in the overall change by a linear mixed effect model $(P=0.66,0.63,0.66)$. While there was no difference in absolute monocyte count and global change between ARDS and non-ARDS over time had no difference between these groups $(P=0.40)$.

\section{Clinical features and area under the curve of Lymphopenia associated ARDS with COVID-19}

To explore the risk factors of clinical features associated with ARDS in COVID-19 patients, lymphocyte count, age $>60 \mathrm{y}$, comorbidities, and APACHE II scores were chosen in this study. Multiple logistic regression results showed that only persistent lymphopenia (OR 3.94, 95\% Cl 1.26-12.33, $\mathrm{P}=0.018$ ) was obviously associated with ARDS (Table 3). The AU-ROC curve of lymphocyte count on day0, day3, day7 predicting ARDS with COVID-19 were $0.72,0.82,0.70$, and the cutoff were $1.2,0.9,0.94\left(\times 10^{9} / \mathrm{L}\right)$ with a sensitivity of $86 \%, 88 \%, 71 \%$, specificity $49 \%, 74 \%, 62 \%$, respectively. (Table 4 , Fig3)

\section{Discussion}

Severe COVID-19 is a life-threatening multi-organ functional injury caused by a dysregulated host response to SARS-CoV-2 and characterized refractory hypoxemia by ARDS. Although some drugs or ways may be useful in treating COVID-19(13,14), human immune factors also play a significant role. Early evaluation of the patient's immune function is essential for immune-stimulating therapy of severe COVID19. Information regarding the immune phenotype in COVID-19 patients is vital before any consideration of immune-stimulating interventions occurs. The current study provides new findings in this field and offers potential insight into the areas for further research.

The phenomenon of lymphocyte depletion observed as evidenced by autopsy studies that had demonstrated ongoing fewer bone marrow lymphocytes, smaller splenic lymph nodes, and functional defects in immune effector cells in patients who have died of COVID-19(5). Many patients with COVID-19 develop persistent immunosuppression before death(4). In the current study, no one patient died before the seven days after confirmed COVID-19, and 17.6\% (21/125) patients had been confirmed ARDS. This study demonstrated that a persistently low level of lymphocytes on the 7th day following confirmed COVID-19 independently predicts ARDS and may serve as a biomarker for COVID-19-induced immunosuppression.

Similar to the prior study $(15,16)$, absolute lymphocyte counts are easily measured in most clinical laboratories and are already frequently obtained in COVID-19 patients. A previous study had demonstrated persistently decreased levels of absolute lymphocyte count with non-survivors, while survivors experience lymphocyte recovery with sepsis(17). They theorized that lymphocytes recruited and lymphocyte apoptosis with the development of sepsis(17). It is a routine test that could be used both clinically and in future trials of COVID-19 therapies to identify the patients at highest risk for immunosuppression.

For this study, we focused on day seven absolute lymphocyte counts based on the mean hospital lengths of stay about two weeks, indicating that lymphocyte counts on this day would be a therapeutic window 
watershed. For those who were discharged, the time from onset to ARDS 8.0 days(18). The time point at which patients with COVID-19 is likely extremely variable because of pathogen and host immune. Therefore, we also analyzed days 0, 3, 7 lymphocyte counts in the subset of patients who had complete blood counts measured to determine whether persistent lymphopenia at an earlier time point could also predict ARDS. We found that day 0, 3, 7 absolute lymphocyte counts were associated with ARDS after accounting for other covariates, and the AUC were $0.72,0.82$. 0.70 , and the cutoff were $1.2,0.9,0.94$ $\left(\times 10^{9} / \mathrm{L}\right)$ with a sensitivity of $86 \%, 88 \%, 71 \%$, specificity $49 \%, 74 \%, 62 \%$, respectively. The results showed that immune-stimulating therapy was administrated three days at the earliest and seven days at the latest. Despite this, determining the time at which continued lymphopenia clinically requires consideration of the effects of drugs, such as ribavirin and corticosteroids et al.

Lymphopenia was defined as an absolute lymphocyte count of less than $1.0 \times 10^{9} / \mathrm{L}$. Younger adults with persistent unexplained moderate to severe lymphopenia should consider infection, especially Viral (including HIV, influenza, hepatitis) and in those with unexplained moderate to severe lymphopenia (lymphocyte count $<1 \times 10^{9} / \mathrm{L}$ ) offer HIV testing(19). The lymphopenia was also conformed in nonsurvivors with COVID-19, and the lymphocyte counts continued to decrease until death occurred(17). Similarly, our study showed severe COVID-19 patients had lymphopenia. Lymphoproliferative disorders can also be associated with the reduction of immunoglobulin levels(19). Administrated a specific isotype (such as $\lg$, IgA, IgM) may help patients with COVID-19 patients. In the future, larger studies stratifying patients by age, comorbidities, or APACHE II score may clarify whether different absolute lymphocyte cutoff values would be more useful in specific subpopulations of patients with COVID-19. Multiple logistic regression results showed that only persistent lymphopenia (OR 3.94, 95\% Cl 1.26-12.33, $\mathrm{P}=0.018$ ) was obviously associated with ARDS induced by COVID-19, indicating that the proportion of ARDS with persistent lymphopenia $\left(<1 \times 10^{9} / L\right)$ was 3.94 times that of non-persistent lymphopenia induced by COVID-19. Therefore, using persistent lymphopenia can identify potential ARDS patients with COVID-19.

\section{Limitations}

This study has several limitations. As a single-center cohort study, it was prone to limitations inherent in this study design, such as an imbalance between the study groups. We attempted to account for major care-related and patient-specific determinants by adjusting for age, comorbidities, and APACHE II score in a multivariable model. Instead, we used the development of vital organ dysfunction and hospital lengths of stay as a clinically relevant surrogate marker of immunosuppression. As we advance, future clinical trials in this area should measure not only biomarkers of immunosuppression, but also clinical outcomes to establish causation further. Another limitation of this study is those exclusion patients. According to the Chinese government treatment principle "early detection, early diagnosis, early isolation and early treatment" required for patients with COVID-19, the lack of blood routine results in these patients indicates the patients have not apparent symptoms. As a result, the intensivists did not test the blood routine for the patient timely. Therefore, the excluded 24 cases would have some effects on the outcome. Finally, the 
main limitation of this study that the results do not allow us to conclude whether persistent lymphopenia directly contributes to ARDS induced by COVID-19 or whether it is simply a biomarker of immunosuppression or immunodepletion. We are also not able to presume that immune-stimulatory therapy aimed at reversing lymphopenia would reduce the incidence of ARDS. Nevertheless, prospective studies are needed to establish lymphopenia as a causative factor in the progression of ARDS induced by COVID-19.

\section{Conclusion}

In summary, persistent lymphopenia for one week predicts ARDS associated with COVID-19. In the clinical setting, a persistent lymphopenia in patients with COVID-19 should prompt intensivists to re-evaluate their patients' response to antiviral therapy and assess for the presence of multiple drug-resistant infections secondary to hospital. In the future, COVID-19 treatments could be tailored to individuals' immunological phenotypes. Potential immunotherapeutic agents, such as interleukin seven and anti-programmed cell death one receptor antibody, prevent T-cell immunodepletion.

\section{Declarations}

\section{Ethics approval and consent to participate:}

The Second People's Hospital approved the study protocol of Shenzhen \& First Affiliated Hospital of Shenzhen University (institutional review board number 202003009004).

\section{Consent for publication:}

Written informed consent for publication was obtained from all participants.

\section{Availability of data and materials:}

The study analyzed de-identified data from the hospital's healthcare informatics group, which was supervised by the Shenzhen Municipal Health Commission. The datasets analyzed during the current study are available from the corresponding author on reasonable request.

\section{Author Contributions:}

Drs $\mathrm{R}$ Chen and D Ren had full access to all of the data in the study and take responsibility for the integrity of the data;

Statistical analysis: Z Zou

Concept and design: $\mathrm{M}$ Wu

Drafting of the manuscript: Z Zou and M Wu 
Administrative, technical, or material support: R Chen, D Ren, B Yu, Y Feng.

Drs Y Feng contributed equally to this article.

Obtained funding: $\mathrm{M}$ Wu, Y Feng

\section{Conflict of Interest Disclosures:}

The authors have no financial conflicts of interest.

\section{Funding/Support:}

This work was supported囚in part, by grants from Sanming Project of Medicine in Shenzhen (SZSM20162011). Shenzhen Science and Technology Innovation Commission (No. JCYJ20160425103130218, JCYJ20170306091335008). And Clinical Research Project of Health and Family Planning Commission of Shenzhen Municipality (SZLY2017007)

\section{Acknowledgments:}

We thank Dr. Hao-li Li and Dr. Yan Liu from the Second People's Hospital of Shenzhen, and anonymous reviewers for their useful comments and language editing, which have greatly improved the manuscript.

\section{References}

1. Zhang H, Penninger JM, Li Y, Zhong N, Slutsky AS. Angiotensin-converting enzyme 2 (ACE2) as a SARS-CoV-2 receptor: molecular mechanisms and potential therapeutic target. Intensive care medicine. 2020;46(4):586-90.

2. Angus DC, van der Poll T. Severe sepsis and septic shock. The New England journal of medicine. 2013;369(9):840-51.

3. Ward PA. Immunosuppression in sepsis. Jama. 2011;306(23):2618-9.

4. Yang X, Yu Y, Xu J, Shu H, Xia J, Liu H, et al. Clinical course and outcomes of critically ill patients with SARS-CoV-2 pneumonia in Wuhan, China: a single-centered, retrospective, observational study. The Lancet Respiratory medicine. 2020;8(5):475-81.

5. Xu Z, Shi L, Wang Y, Zhang J, Huang L, Zhang C, et al. Pathological findings of COVID-19 associated with acute respiratory distress syndrome. The Lancet Respiratory medicine. 2020;8(4):420-2.

6. Hotchkiss RS, Karl IE. The pathophysiology and treatment of sepsis. The New England journal of medicine. 2003;348(2):138-50.

7. Schefold JC, Hasper D, Volk HD, Reinke P. Sepsis: time has come to focus on the later stages. Medical hypotheses. 2008;71(2):203-8.

8. Adrie C, Lugosi M, Sonneville R, Souweine B, Ruckly S, Cartier JC, et al. Persistent lymphopenia is a risk factor for ICU-acquired infections and for death in ICU patients with sustained hypotension at admission. Annals of intensive care. 2017;7(1):30. 
9. Wu C, Chen X, Cai Y, Xia J, Zhou X, Xu S, et al. Risk Factors Associated With Acute Respiratory Distress Syndrome and Death in Patients With Coronavirus Disease 2019 Pneumonia in Wuhan, China. JAMA internal medicine. 2020;180(7):1-11.

10. World Health Organization. Clinical management of severe acute respiratory infection when novel coronavirus (2019-nCoV) infection is suspected: interim guidance. January 28, 2020. (https://www.who.int/docs/default-source/coronaviruse/clinical-management-of-novelcov.pdf.opens in new tab) .

11. Stevens PE, Levin A. Evaluation and management of chronic kidney disease: synopsis of the kidney disease: improving global outcomes 2012 clinical practice guideline. Annals of internal medicine. 2013;158(11):825-30.

12. Kobashi H, Toshimori J, Yamamoto K. Sepsis-associated liver injury: Incidence, classification and the clinical significance. Hepatology research : the official journal of the Japan Society of Hepatology. 2013;43(3):255-66.

13. Bloch EM, Shoham S, Casadevall A, Sachais BS, Shaz B, Winters JL, et al. Deployment of convalescent plasma for the prevention and treatment of COVID-19. The Journal of clinical investigation. 2020;130(6):2757-65.

14. Luo P, Liu Y, Qiu L, Liu X, Liu D, Li J. Tocilizumab treatment in COVID-19: A single center experience. Journal of medical virology. 2020;92(7):814-8.

15. Zhu N, Zhang D, Wang W, Li X, Yang B, Song J, et al. A Novel Coronavirus from Patients with Pneumonia in China, 2019. The New England journal of medicine. 2020;382(8):727-33.

16. Wang D, Hu B, Hu C, Zhu F, Liu X, Zhang J, et al. Clinical Characteristics of 138 Hospitalized Patients With 2019 Novel Coronavirus-Infected Pneumonia in Wuhan, China. Jama. 2020;323(11):1061-9.

17. Drewry AM, Samra N, Skrupky LP, Fuller BM, Compton SM, Hotchkiss RS. Persistent lymphopenia after diagnosis of sepsis predicts mortality. Shock (Augusta, Ga). 2014;42(5):383-91.

18. Guan WJ, Ni ZY, Hu Y, Liang WH, Ou CQ, He JX, et al. Clinical Characteristics of Coronavirus Disease 2019 in China. The New England journal of medicine. 2020;382(18):1708-20.

19. Brass D, McKay P, Scott F. Investigating an incidental finding of lymphopenia. BMJ (Clinical research ed). 2014;348:g1721.

\section{Tables}

Table1 Baseline characteristics of ARDS and non-ARDS associated COVID-19 


\begin{tabular}{|c|c|c|c|c|}
\hline & Total $(n=125)$ & $\begin{array}{l}\text { Non- } \\
\text { ARDS(n=103) }\end{array}$ & $\operatorname{ARDS}(n=22)$ & $\begin{array}{l}P \\
\text { value }\end{array}$ \\
\hline Age $(y r)$, mean $\pm S D$ & $52.4 \pm 15.4$ & $51.2 \pm 15.9$ & $58.0 \pm 11.5$ & 0.026 \\
\hline \multicolumn{4}{|l|}{$\begin{array}{l}\text { Classification of age (yr), } \\
\mathrm{N}(\%)\end{array}$} & 0.005 \\
\hline$\leq 50$ & $50(40.0 \%)$ & $47(45.6)$ & $3(13.6)$ & \\
\hline$>50$ & $75(60.0 \%)$ & $56(54.4)$ & 19(86.4) & \\
\hline Male, N (\%) & $73(58.4)$ & $58(56.3)$ & $15(68.2)$ & 0.305 \\
\hline $\begin{array}{l}\text { Temperature }\left({ }^{\circ} \mathrm{C}\right) \text {, mean } \\
\pm S D\end{array}$ & $37.5 \pm 0.9$ & $37.5 \pm 0.9$ & $37.5 \pm 0.9$ & 0.982 \\
\hline \multicolumn{4}{|c|}{ Classification of body Temperature $\left({ }^{\circ} \mathrm{C}\right), \mathrm{N}(\%)$} & 0.981 \\
\hline$<37.3$ & $55(44.0)$ & $45(43.7)$ & $10(45.5)$ & \\
\hline $37.3-38.0$ & $38(30.4)$ & $31(30.1)$ & $7(31.8)$ & \\
\hline $38.1-39.0$ & $27(21.6)$ & 23(22.3) & $4(18.2)$ & \\
\hline$>39.0$ & $5(4.0)$ & $4(3.9)$ & $1(4.6)$ & \\
\hline Comorbidities, N (\%) & $34(27.2)$ & $27(26.2)$ & $7(31.8)$ & 0.592 \\
\hline Hypertension & $21(16.8)$ & $16(15.5)$ & $5(22.7)$ & 0.529 \\
\hline Diabetes & $12(9.6)$ & $9(8.7)$ & $3(13.6)$ & 0.442 \\
\hline Coronary heart disease & $8(6.4)$ & $7(6.8)$ & $1(4.5)$ & 1.000 \\
\hline Cerebrovascular disease & $2(1.6)$ & $2(1.9)$ & $0(0.0)$ & 1.000 \\
\hline COPD & $3(2.4)$ & $2(1.9)$ & $1(4.5)$ & 0.443 \\
\hline Malignancy & $3(2.4)$ & $2(1.9)$ & $1(4.5)$ & 0.443 \\
\hline $\begin{array}{l}\text { Heart rate(bpm), mean } \\
\pm S D\end{array}$ & $91.3 \pm 12.4$ & $90.3 \pm 11.9$ & $95.9 \pm 14.1$ & 0.094 \\
\hline Respiration rate(bpm) & $20.5 \pm 2.4$ & $20.1 \pm 1.6$ & $22.4 \pm 4.1$ & 0.019 \\
\hline$>24$ breaths per min & $7(5.6)$ & $2(1.9)$ & $5(22.7)$ & 0.002 \\
\hline Hubei exposure, $\mathrm{N}(\%)$ & 112(89.6) & $96(93.2)$ & 16(72.7) & 0.004 \\
\hline $\begin{array}{l}\text { Signs and symptoms, N } \\
(\%)\end{array}$ & $120(96.0)$ & $99(96.1)$ & $21(95.5)$ & 1.000 \\
\hline Fever & $110(88.0)$ & $90(87.4)$ & $20(90.9)$ & 1.000 \\
\hline Fatigue & $31(24.8)$ & $24(23.3)$ & $7(31.8)$ & 0.401 \\
\hline Muscle pain & $31(24.8)$ & $25(24.3)$ & $6(27.3)$ & 0.767 \\
\hline
\end{tabular}




\begin{tabular}{|c|c|c|c|c|}
\hline Dry cough & $36(28.8)$ & $31(30.1)$ & $5(22.7)$ & 0.608 \\
\hline Expectoration & $34(27.2)$ & $25(24.3)$ & $9(40.9)$ & 0.111 \\
\hline Chest tightness & $11(8.8)$ & $9(8.7)$ & $2(9.1)$ & 1.000 \\
\hline Dyspnea & $3(2.4)$ & $1(1.0)$ & $2(9.1)$ & 0.080 \\
\hline Bellyache & $2(1.6)$ & $2(1.9)$ & $0(0.0)$ & 1.000 \\
\hline Diarrhea & $9(7.2)$ & $8(7.8)$ & $1(4.5)$ & 1.000 \\
\hline Nausea & $5(4.0)$ & $4(3.9)$ & $1(4.5)$ & 1.000 \\
\hline Vomit & $1(0.8)$ & $1(1.0)$ & $0(0.0)$ & 1.000 \\
\hline Inappetence & $10(8.0)$ & $6(5.8)$ & $4(18.2)$ & 0.074 \\
\hline Headache & $10(8.0)$ & $10(9.7)$ & $0(0.0)$ & 0.128 \\
\hline Dizziness & $10(8.0)$ & $8(7.8)$ & $2(9.1)$ & 0.689 \\
\hline РСТ (ng/ml), median(IQR) & $0.06(0.04,0.07)$ & $0.05(0.03,0.07)$ & $0.08(0.06,0.13)$ & 0.002 \\
\hline CRP $(\mathrm{mg} / \mathrm{dl})$, median(IQR) & $22.3(9.1,44.7)$ & $19.5(8.7,32.9)$ & $55.4(34.1,86.1)$ & $<.001$ \\
\hline IL-6 (pg/ml), median(IQR) & $20.4(13.1,43.0)$ & $19.4(12.2,30.2)$ & $34.5(16.0,79.5)$ & 0.035 \\
\hline $\begin{array}{l}\text { WBC }(1 \times 109 / L) \\
\text { median(IQR) }\end{array}$ & $4.8(3.8,6.1)$ & $4.7(3.6,5.9)$ & $5.5(4.3,6.8)$ & 0.061 \\
\hline $\mathrm{HGB}(\mathrm{g} / \mathrm{L})$, mean $\pm \mathrm{SD}$ & $138.29 \pm 15.57$ & $137.46 \pm 15.76$ & $141.91 \pm 14.49$ & 0.210 \\
\hline $\begin{array}{l}\text { Neutrophils }\left(1 \times 10^{9} / \mathrm{L}\right) \text {, } \\
\text { median(IQR) }\end{array}$ & $2.98(2.23,4.04)$ & $2.81(2.23,3.72)$ & $4.12(2.39,5.63)$ & 0.009 \\
\hline $\begin{array}{l}\text { Lymphocyte }\left(1 \times 10^{9} / \mathrm{L}\right) \text {, } \\
\text { median(IQR) }\end{array}$ & $1.18(0.91,1.58)$ & $1.20(0.97,1.68)$ & $0.94(0.62,1.18)$ & 0.002 \\
\hline Monocytes, median(IQR) & $0.45(0.33,0.58)$ & $0.47(0.35,0.59)$ & $0.38(0.25,0.54)$ & 0.113 \\
\hline $\begin{array}{l}\text { Platelets }\left(1 \times 10^{9} / \mathrm{L}\right) \text {, mean } \\
\pm S D\end{array}$ & $171.57 \pm 53.88$ & $172.65 \pm 54.49$ & $166.86 \pm 52.10$ & 0.645 \\
\hline NLR, median(IQR) & $2.53(1.52,4.34)$ & $2.34(1.42,3.36)$ & $5.10(2.47,5.96)$ & $<.001$ \\
\hline PLR, median(IQR) & $136.9(109.0,185.0)$ & $\begin{array}{l}133.7 \\
(104.9,170.5)\end{array}$ & $194.6(127.5,264.6)$ & 0.003 \\
\hline LMR, median(IQR) & $2.70(2.02,3.63)$ & $2.72(2.12,3.58)$ & $2.28(1.40,3.63)$ & 0.178 \\
\hline Albumin $(\mathrm{g} / \mathrm{L})$, mean $\pm S D$ & $41.57 \pm 3.73$ & $42.24 \pm 3.54$ & $38.68 \pm 3.19$ & $<.001$ \\
\hline $\begin{array}{l}\text { TBiL }(\mu \mathrm{mol} / \mathrm{L}) \\
\text { median(IQR) }\end{array}$ & $9.6(7.5,13.1)$ & $9.3(7.1,13.0)$ & $10.8(9.5,15.5)$ & 0.046 \\
\hline $\operatorname{ALT}(\mathrm{U} / \mathrm{L}), \operatorname{median}(\mathrm{IQR})$ & $23.0(17.0,34.6)$ & $20.5(16.0,33.0)$ & $32.7(22.5,55.9)$ & 0.002 \\
\hline
\end{tabular}




\begin{tabular}{|c|c|c|c|c|}
\hline AST (U/L), median(IQR) & $29.0(23.0,42.4)$ & $27.0(22.0,36.1)$ & $45.6(37.0,59.7)$ & $<.001$ \\
\hline $\begin{array}{l}\text { Creatinine }(\mu \mathrm{mol} / \mathrm{L}) \text {, } \\
\text { median(IQR) }\end{array}$ & $73.71 \pm 25.35$ & $72.50 \pm 21.88$ & $79.00 \pm 37.11$ & 0.437 \\
\hline $\mathrm{pH}$, mean $\pm S \mathrm{SD}$ & $7.43 \pm 0.03$ & $7.43 \pm 0.02$ & $7.44 \pm 0.05$ & 0.345 \\
\hline $\mathrm{P} 02$, mean $\pm \mathrm{SD}$ & $88.18 \pm 22.94$ & $92.80 \pm 23.44$ & $73.72 \pm 13.69$ & $<.001$ \\
\hline $\mathrm{PCO} 2$, mean $\pm \mathrm{SD}$ & $37.05 \pm 4.36$ & $37.30 \pm 3.66$ & $36.26 \pm 6.10$ & 0.456 \\
\hline PO2/Fi02, median(IQR) & $366.34 \pm 121.59$ & $413.37 \pm 95.60$ & $218.83 \pm 60.84$ & $<.001$ \\
\hline PT (s), mean \pm SD & $12.07 \pm 0.97$ & $11.92 \pm 0.93$ & $12.64 \pm 0.96$ & 0.003 \\
\hline APTT (s), mean $\pm S D$ & $37.08 \pm 7.18$ & $36.52 \pm 4.32$ & $39.31 \pm 13.50$ & 0.348 \\
\hline INR, mean \pm SD & $0.90 \pm 0.09$ & $0.89 \pm 0.08$ & $0.96 \pm 0.09$ & 0.003 \\
\hline $\begin{array}{l}\text { D-Dimer (mg/L), } \\
\text { median(IQR) }\end{array}$ & $0.44(0.31,0.74)$ & $0.41(0.30,0.60)$ & $0.85(0.48,1.09)$ & $<.001$ \\
\hline FIB $(g / L)$, mean $\pm S D$ & $4.33 \pm 1.05$ & $4.17 \pm 0.90$ & $4.98 \pm 1.34$ & 0.012 \\
\hline Cholinesterase & $7423.06 \pm 1673.23$ & $7685.37 \pm 1630.56$ & $6623.63 \pm 1578.80$ & 0.012 \\
\hline Admission to ICU & $38(30.4)$ & $24(23.3)$ & $14(63.6)$ & $<.001$ \\
\hline $\begin{array}{l}\text { APACHE II score, median } \\
\text { (IQR) }\end{array}$ & $5.0(2.0,6.0)$ & $4.0(2.0,6.0)$ & $6.0(4.0,9.0)$ & 0.009 \\
\hline
\end{tabular}

Abbreviations: $\mathrm{BMI}$, body mass index; bpm: beats per minute; IQR, interquartile range; COPD, chronic obstructive pulmonary disease; PCT, procalcitonin; CRP, C-reaction protein; WBC, white blood cell; RBC, red blood cell; HGB, haemoglobin; NLR, neutrophil lymphocyte ratio; PLR, platelets lymphocyte ratio; LMR, lymphocyte Monocytes ratio; TBIL, total bilirubin; ALT, alanine aminotransferase; AST, aspartate aminotransferase; BUN, blood urea nitrogen; PT, prothrombin time; APTT, activated partial thromboplastin time; FIB, fibrinogen. APACHE II, Acute Physiology and Chronic Health Evaluation

Table2 Characteristics and outcomes of patients stratified lymphocyte count within the first seven-days after admission 


\begin{tabular}{|c|c|c|c|c|}
\hline & $\begin{array}{l}\text { No } \\
\text { Lymphopenia } \\
(n=79)\end{array}$ & $\begin{array}{l}\text { Persistent } \\
\text { Lymphopenia }(n=35)\end{array}$ & $\begin{array}{l}\text { Lymphopenia and return } \\
\text { to normal }(n=11)\end{array}$ & $\begin{array}{l}\mathrm{P} \\
\text { value }\end{array}$ \\
\hline Age $(y r)$, mean $\pm S D$ & $49.00 \pm 16.47$ & $60.91 \pm 9.85$ & $49.73 \pm 11.97$ & 0.026 \\
\hline Male, N(\%) & $42(53.2)$ & $27(77.1)$ & $4(36.4)$ & 0.015 \\
\hline $\begin{array}{l}\text { Temperature }\left({ }^{\circ} \mathrm{C}\right) \text {,mean } \\
\pm S D\end{array}$ & $37.38 \pm 0.83$ & $37.79 \pm 0.83$ & $37.44 \pm 0.84$ & 0.982 \\
\hline Comorbidities, N(\%) & 16(20.3) & $16(45.7)$ & $2(18.2)$ & 0.015 \\
\hline Hypertension & $9(11.4)$ & $11(31.4)$ & $1(9.1)$ & 0.029 \\
\hline Diabetes & $5(6.3)$ & $6(17.1)$ & $1(9.1)$ & 0.200 \\
\hline $\begin{array}{l}\text { Coronary heart } \\
\text { disease }\end{array}$ & $4(5.1)$ & $4(11.4)$ & $0(0.0)$ & 0.339 \\
\hline $\begin{array}{l}\text { Cerebrovascular } \\
\text { disease }\end{array}$ & $1(1.3)$ & $1(2.9)$ & $0(0.0)$ & 0.603 \\
\hline COPD & $3(3.8)$ & $0(0.0)$ & $0(0.0)$ & 0.661 \\
\hline Malignancy & $2(2.5)$ & $1(2.9)$ & $0(0.0)$ & 1.000 \\
\hline $\begin{array}{l}\text { Heart rate(bpm), mean } \\
\pm S D\end{array}$ & $89.87 \pm 13.14$ & $95.57 \pm 10.81$ & $87.64 \pm 8.14$ & 0.094 \\
\hline Respiration rate(bpm) & $20.01 \pm 1.41$ & $21.60 \pm 3.55$ & $20.73 \pm 2.24$ & 0.019 \\
\hline Hubei exposure, $N(\%)$ & $75(94.9)$ & 27(77.1) & 10(90.9) & 0.014 \\
\hline $\begin{array}{l}\text { Signs and symptoms, } \\
\mathrm{N}(\%)\end{array}$ & 75(94.9) & $34(97.1)$ & 11(100.0) & 1.000 \\
\hline Fever & $67(84.8)$ & $33(94.3)$ & 10(90.9) & 0.426 \\
\hline Fatigue & $17(21.5)$ & 13(37.1) & $1(9.1)$ & 0.112 \\
\hline Muscle pain & 15(19.0) & $12(34.3)$ & $4(36.4)$ & 0.138 \\
\hline Dry cough & $22(27.8)$ & $8(22.9)$ & $6(54.5)$ & 0.143 \\
\hline Expectoration & $20(25.3)$ & $12(34.3)$ & $2(18.2)$ & 0.545 \\
\hline Chest tightness & $7(8.9)$ & $4(11.4)$ & $0(0.0)$ & 0.617 \\
\hline Dyspnea & $0(0.0)$ & $3(8.6)$ & $0(0.0)$ & 0.061 \\
\hline Bellyache & $0(0.0)$ & $1(2.9)$ & $1(9.1)$ & 0.057 \\
\hline Diarrhea & $4(5.1)$ & $5(14.3)$ & $0(0.0)$ & 0.158 \\
\hline Nausea & $2(2.5)$ & $3(8.6)$ & $0(0.0)$ & 0.349 \\
\hline
\end{tabular}




\begin{tabular}{|lllll|}
\hline Vomit & $1(1.3)$ & $0(0.0)$ & $0(0.0)$ & 1.000 \\
\hline Inappetence & $5(6.3)$ & $5(14.3)$ & $0(0.0)$ & 0.277 \\
\hline Headache & $9(11.4)$ & $0(0.0)$ & $1(9.1)$ & 0.095 \\
\hline Invziness & $6(7.6)$ & $3(8.6)$ & $1(9.1)$ & 1.000 \\
\hline $\begin{array}{l}\text { Noninvasive } \\
\text { ventilation }\end{array}$ & $18(22.8)$ & $26(74.3)$ & $1(9.1)$ & $<0.001$ \\
\hline $\begin{array}{l}\text { APACHE II score, } \\
\text { median (IQR) }\end{array}$ & $4.0(1.0,6.0)$ & $6.0(5.0,9.0)$ & $2(18.2)$ & $<0.001$ \\
\hline Admission to ICU & $12(15.2)$ & $24(68.6)$ & $3.0(2.0,6.0)$ & $<0.001$ \\
\hline LOS(d), median(IQR) & $16(14,24)$ & $28(24,36)$ & $15(13,23)$ & $<0.001$ \\
\hline AKI & $1(1.3)$ & $4(11.4)$ & $0(0.0)$ & 0.001 \\
\hline AHI & $0(0.0)$ & $2(5.7)$ & $0(0.0)$ & 0.039 \\
\hline Shock & $3(3.8)$ & $6(17.1)$ & $0(0.0)$ & 0.032 \\
\hline ACD & $0(0.0)$ & $3(8.6)$ & $0(0.0)$ & 0.061 \\
\hline ARDS & $7(8.9)$ & $13(37.1)$ & $2(18.2)$ & 0.001 \\
\hline
\end{tabular}

Abbreviations: bpm: beats per minute; IQR, interquartile range; COPD, chronic obstructive pulmonary disease; APACHE II, Acute Physiology and Chronic Health Evaluation; ICU: intensive care unit; ARDS, acute respiratory distress syndrome; $A K I$, acute kidney injury; $A H I$, acute hepatic injury; $A C D$, acute cardiac dysfunction; ICU, intensive care unit; LOS, length of stay; IQR: interquartile range

Table 3 Multivariable analysis of clinical features associated with ARDS

\begin{tabular}{|llll|}
\hline & Adjusted ORa $(95 \% \mathrm{Cl})$ & Wald & p value \\
\hline lymphocyte count division & & & \\
\hline No Lymphopenia & 1 & & \\
\hline Persistent Lymphopenia & $3.94(1.26,12.33)$ & 5.566 & 0.018 \\
\hline Lymphopenia and return to normal & $2.19(0.38,12.67)$ & 0.768 & 0.381 \\
\hline Age $>60 y$ & $0.38(0.08,1.69)$ & 1.634 & 0.201 \\
\hline Comorbidities & $2.09(0.63,6.9)$ & 1.455 & 0.228 \\
\hline APACHE II score & $1.12(0.93,1.34)$ & 1.384 & 0.240 \\
\hline
\end{tabular}


APACHE II, Acute Physiology and Chronic Health Evaluation

Table 4 Cutoff and ROC curve of lymphocyte count predicting ARDS with COVID-19

\begin{tabular}{|lllll|}
\hline lymphocyte count & AUC $(95 \% \mathrm{Cl})$ & Cutoff & sensitivity & specificity \\
\hline Day 0 & $0.72(0.63-0.79)$ & 1.20 & 0.86 & 0.49 \\
\hline Day 3 & $0.82(0.75-0.91)$ & 0.90 & 0.88 & 0.74 \\
\hline Day 7 & $0.70(0.56-0.74)$ & 0.94 & 0.71 & 0.62 \\
\hline
\end{tabular}

AUC: area under the curve

Figures 


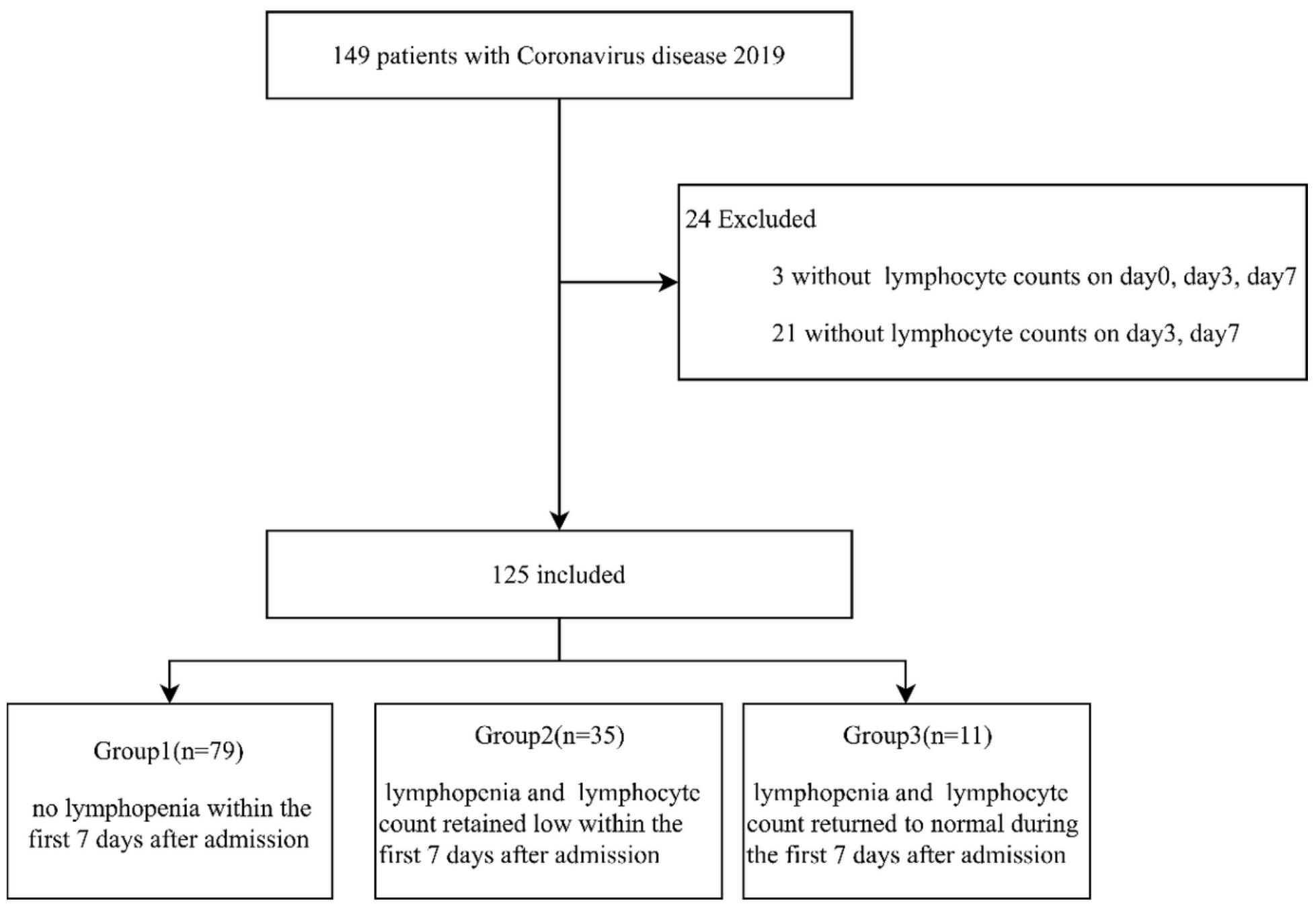

\section{Figure 1}

Flow diagram of study subjects 

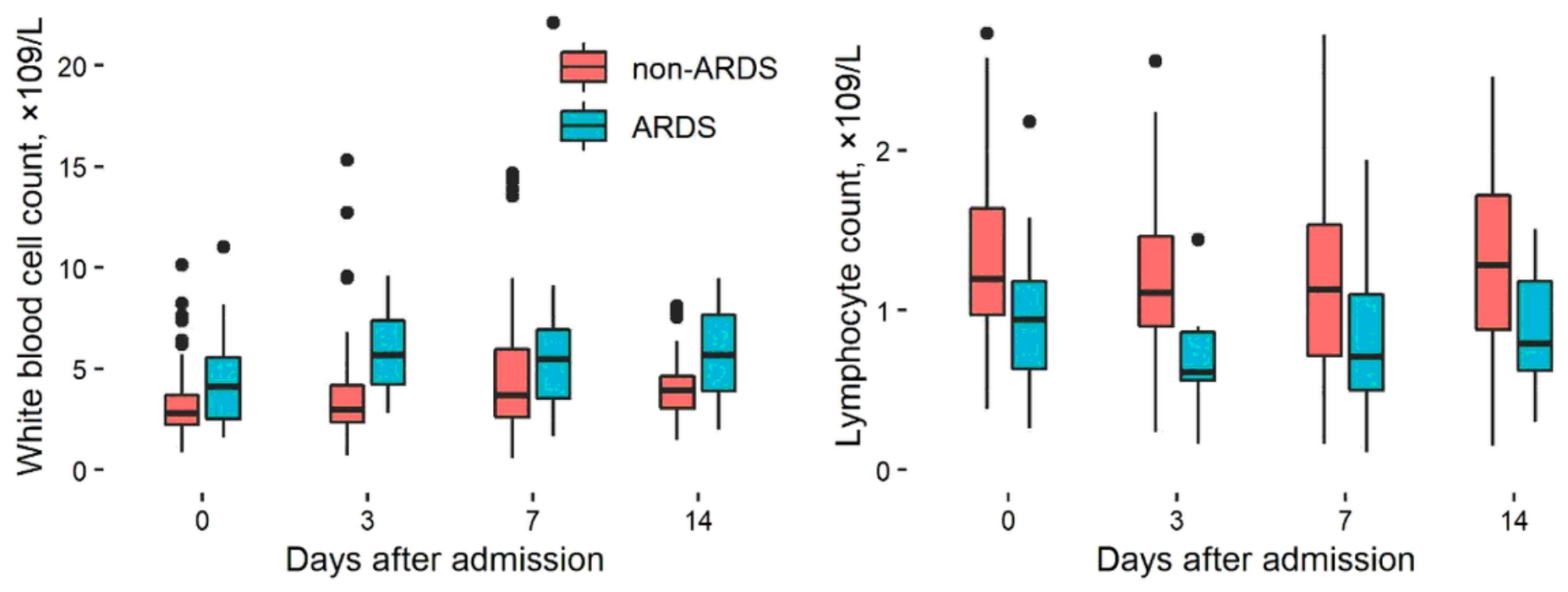

$12.5-$
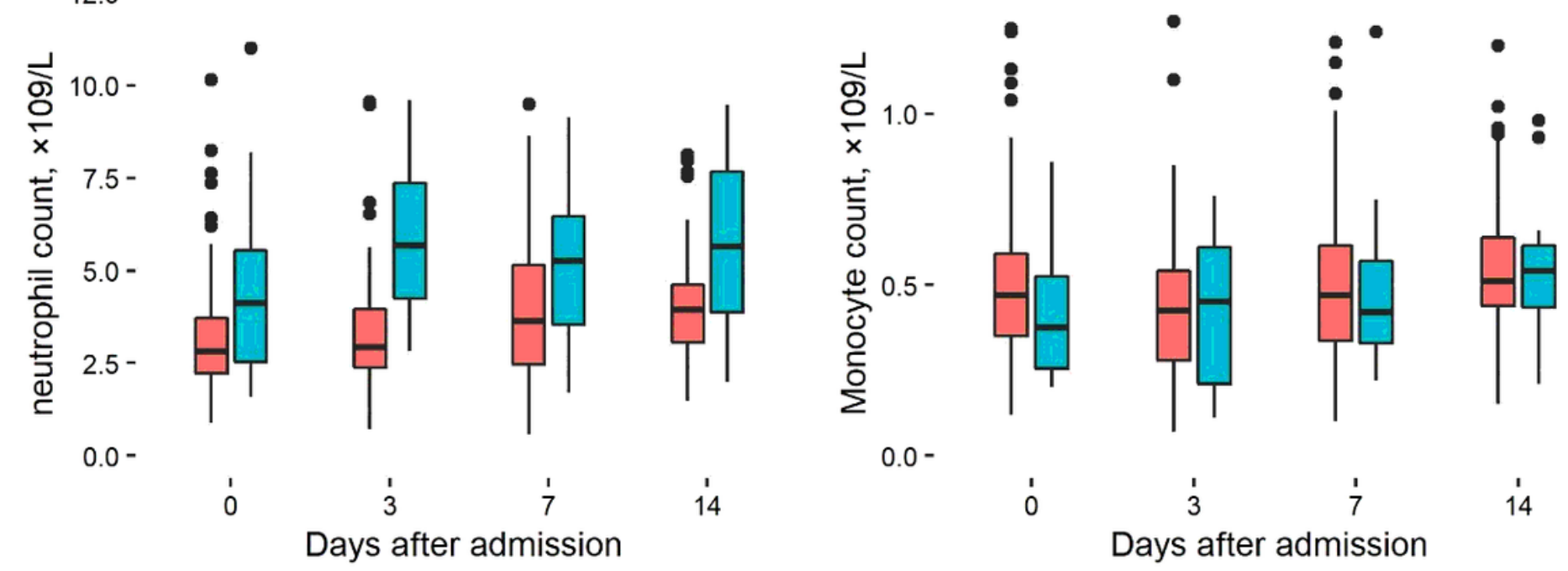

Figure 2

Box plots of leukocyte counts in ARDS and non-ARDS during the first seven days following admission 


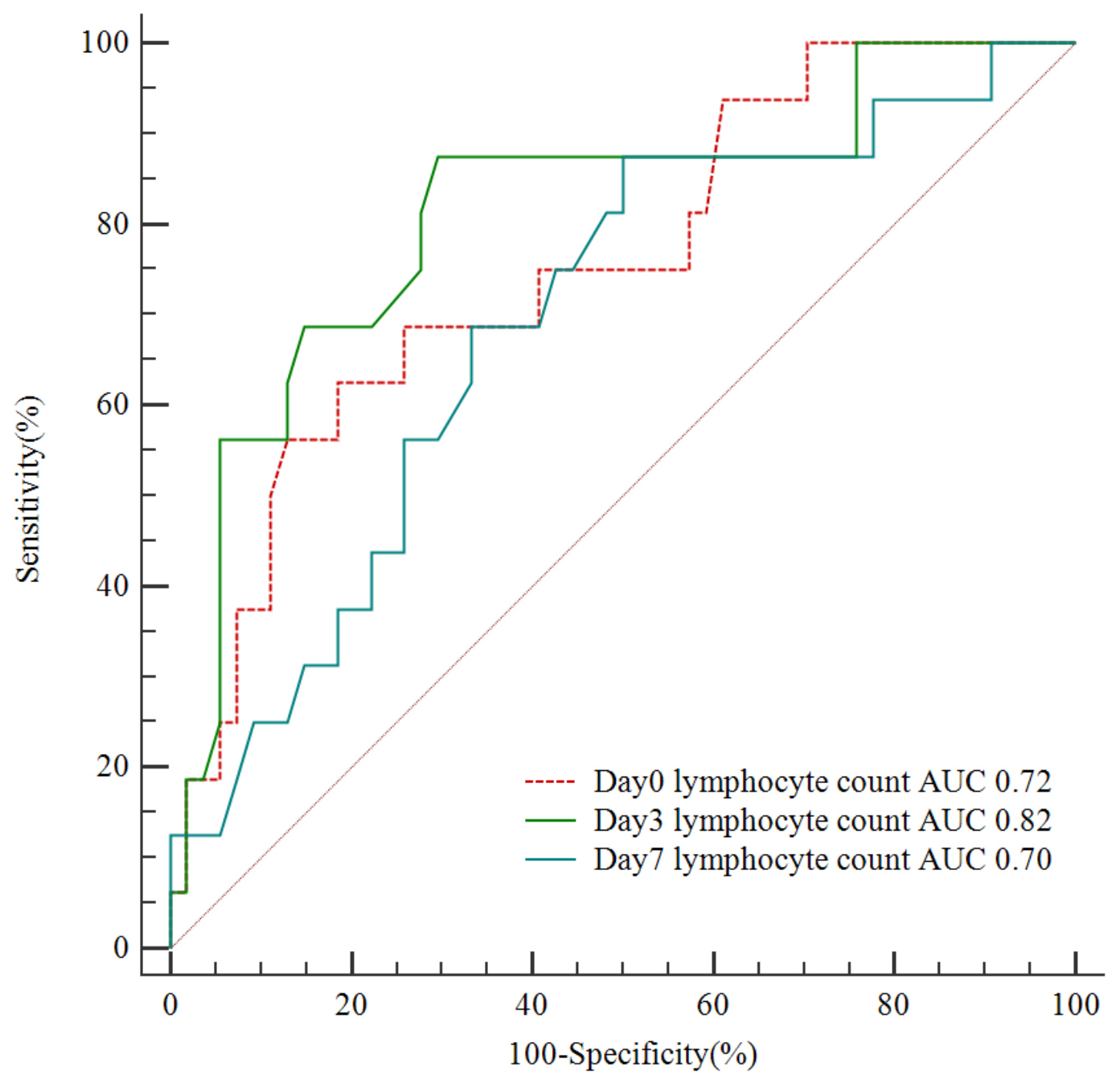

Figure 3

Cutoff and ROC curve of lymphocyte count predicting ARDS with COVID-19 